\title{
Intellectual Property Rights and Crop-Improving R\&D under Adaptive Destruction
}

\author{
Oleg Yerokhin and GianCarlo Moschini
}

Working Paper 07-WP 449

June 2007

\section{Center for Agricultural and Rural Development lowa State University \\ Ames, lowa 50011-1070 \\ www.card.iastate.edu}

\begin{abstract}
Oleg Yerokhin is a Ph.D. candidate and instructor, and GianCarlo Moschini is a professor of economics and the Pioneer Hi-Bred Chair in Science and Technology Policy, both in the Department of Economics, lowa State University.

This paper is available online on the CARD Web site: www.card.iastate.edu. Permission is granted to excerpt or quote this information with appropriate attribution to the authors.

Questions or comments about the contents of this paper should be directed to GianCarlo Moschini, 583 Heady Hall, lowa State University, Ames, IA 50011-1070; Ph: (515) 294-5761; Fax: (515) 294-6336; E-mail: moschini@iastate.edu.
\end{abstract}




\title{
Intellectual Property Rights and Crop-Improving R\&D under Adaptive Destruction
}

\begin{abstract}
This paper studies how the strength of intellectual property rights (IPRs) affects investments in biological innovations when the value of an innovation is stochastically reduced to zero because of the evolution of pest resistance. We frame the problem as a research and development $(\mathrm{R} \& \mathrm{D})$ investment game in a duopoly model of sequential innovation. We characterize the incentives to invest in $\mathrm{R} \& \mathrm{D}$ under two competing IPR regimes, which differ in their treatment of the follow-on innovations that become necessary because of pest adaptation. Depending on the magnitude of the R\&D cost, ex ante firms might prefer an intellectual property regime with or without a "research exemption" provision. The study of the welfare function that also accounts for benefit spillovers to consumers-which is possible analytically under some parametric conditions, and numerically otherwise-shows that the ranking of the two IPR regimes depends critically on the extent of the R\&D cost.
\end{abstract}

Keywords: biological resistance, intellectual property rights, Markov perfect equilibrium, patents, research exemption, $R \& D$, sequential innovation.

JEL Classification: L00, O31, O34, Q28 


\section{Introduction}

A major objective of crop breeding has long been that of improving the resistance of commercial varieties to pests, diseases, and environmental stresses, which are known to cause significant yield reductions. For U.S. agriculture alone, it is estimated that the damage ranges between $\$ 2$ billion and $\$ 7$ billion per year, with an additional $\$ 1.2$ billion spent on various crop protection measures (Palumbi, 2001). The task of improving crop resistance, however, is particularly challenging because the evolution of pest species makes possible the emergence of resistance in the pest population, which leads to the obsolescence over time of past improvements. This calls for continuing and sustained research and development (R\&D) efforts, combining both traditional breeding and newer biotechnology tools, aimed at crop improvements. Furthermore, in an era of declining public support for agricultural research, it is imperative that private $\mathrm{R} \& \mathrm{D}$ activities be encouraged and fostered by suitable policies. In this paper we focus on the role of intellectual property rights, and specifically investigate some implications that arise in the context of innovations that may be rendered ineffective over time because of the onset of pest resistance.

Whereas agricultural biotechnology promises new, powerful tools for crop improvement, the possibility of unintended or unforeseen consequences suggests that some form of government regulation might be necessary (Just, Alston, and Zilberman, 2006; Swanson, 2002). One way to address biotechnology policy issues is through a general economic approach to the optimal management of biological resources that includes methods for valuing existing species in the context of maximizing expected social welfare (Brock and Xepapadeas, 2003). This approach has been used extensively to study the dynamics of the pest adaptation process, and it is often argued that some form of policy intervention may improve welfare because farmers generally lack incentives to take into account the consequences of their pest management practices, including planting decisions. For this reason, the U.S. Environmental Protection Agency has introduced in some cases (in particular in the cases of Bt cotton and Bt corn) regulations that require farmers to plant at least some of their land with crops that are not genetically modified (GM) to slow down the rate of resistance development (Fisher and Laxminarayan, 2005). Such policies are usually analyzed in a bioeconomic model that takes into account interplay between the evolutionary adaptation by pests and economic incentives of farmers (Hurley et al., 2002). 
The effectiveness of such policy creating "crop refuges" has been questioned on purely biological grounds, as well as more generally. Specifically, it has been argued that private breeders should have an incentive to take into account the problem of the evolution of pest resistance, because this process directly affects their profits (Noonan, 2002). Thus, private breeders would ensure that existing pest management techniques are used efficiently and would invest in the development of new technologies to overcome the resistance problem (Fisher and Laxminarayan, 2004).

The literature on optimal resistance management has been of interest for both pest resistance in agriculture and antibiotics resistance in public health, and it is now well understood that economics can be useful in understanding various forms of externalities in both cases (Goeschl and Swanson, 2002a). The economic approach to pest resistance management in agriculture was pioneered by Hueth and Regev (1974). Subsequent studies on the excessive use of pesticides and the possibility of market failure when dealing with the pest resistance problem has yielded important insights, but some see a need to move beyond the renewable/nonrenewable resource framework that has been used so far and to consider other important features of the economic environment (Alix-Garcia and Zilberman, 2005). In particular, the incentive of private sector breeders to invest in crop innovations depends on the delineation of property rights in the various attributes of the new crop varieties, and, therefore, the issues of intellectual property rights and the resulting market structure should occupy a central place in this debate.

Existing research on the interplay between social and private incentives to innovate in the context of the resistance problem leads to some interesting conclusions. First, while society as a whole reaps a large benefit from technologies that decrease the scope of the resistance problem, the benefits are dissipated among many users and thus may not attract sufficient private investments. This point was made by Goeschl and Swanson (2003b), who also note that the nature of innovation in the context of a biological race against nature differs from that of the standard quality ladder model of many innovation and growth models. They coined the term "adaptive destruction" to characterize this process, emphasizing the analogy to and difference from the Schumpeterian paradigm of "creative destruction" (in which each product is eventually superseded by a higher-quality one). Second, as shown by Goeschl and Swanson (2003a), private and social incentives to invest in $\mathrm{R} \& \mathrm{D}$ might diverge with an increase in the degree of adaptive destruction, because the more 
severe is the resistance problem, the lower is the private benefit of crop R\&D and the higher are the social returns from such investment. Goeschl and Swanson (2002b), in the context of an $R \& D$ race with antibiotic resistance, similarly find that private incentives fall short of generating the first-best outcome.

In this paper we explore in more detail how the form and extent of intellectual property rights (IPRs) impact the incentive to innovate and the welfare consequences of innovation, in a context characterized by adaptive destruction. Moschini and Yerokhin (2006) show that a particularly useful characterization of the strength of IPRs for plants consists of whether or not such IPRs contain a "research exemption" or "experimental use" provision. Following that approach, here we compare and contrast the effects of two alternative IPR regimes that capture some essential features of the current institutional setting. The "stronger" IPR mode, referred to as the full patent (FP) regime, corresponds to the standard utility patents (as awarded in the United States by the U.S. Patent and Trademark Office). The relatively "weaker" IPR mode, referred to as the research exemption (RE) regime, corresponds to the so-called plant breeders' rights (PBRs). As we will discuss in more detail, the critical difference between these two IPR modes concerns a feature that bears on the sequential and cumulative nature of innovation, which is a distinctive feature of agricultural and biotechnology innovations.

In addition to the consideration of alternative IPR regimes, in our analysis we also emphasize the importance of the market structure of the innovation industry, a feature largely ignored to date in the analysis of the biological resistance problem. In particular, we build a duopoly model of an $R \& D$ race in which the value of the final product is destroyed with exogenously given probability, thus making the duration of the monopoly power finite even under the (simplifying) assumption of an infinite patent life. Conceptually, this model belongs to the class of symmetric stochastic $\mathrm{R} \& \mathrm{D}$ races in which innovations arrive according to a Poisson process (Reinganum, 1989, provides an early survey of this literature). In addition to addressing the resistance problem, our analysis contributes to the literature on IPR incentives for sequential innovation. Models in this area typically consider the effects of patent length and breadth on the division of profit between the owners of the first and second generations of innovation, both in a sequential setting (Green and Scotchmer, 1995) and in the context of R\&D races (O’Donoghue, 1998; Denicolò, 2000). In contrast to most of these models, we assume that the second generation of the innovation is patentable and 
non-infringing, and we concentrate on the question of whether the first innovator has the right to block all further R\&D activities related to the patented product (i.e., whether or not there exists a research exemption).

In our setting, under the FP regime, the research on the patented product constitutes an infringement. Because of the sequential nature of the innovation process, with this kind of IPR protection the winner of the first race obtains an exclusive right to improve the product in the future. On the other hand, under the RE regime, firms cannot be excluded from participating in any improvement project, so that each improvement stage is a race between two firms. Throughout the analysis, we assume that no licensing takes place, in order to emphasize the effects of the IPR regimes on the incentives for innovation. In the next section, we provide a brief background that illustrates some critical features of our stylized model. We then describe the demand side of the model and lay out the structure of the R\&D model that embeds, among other things, the notion of adaptive destruction. We characterize the Markov perfect equilibria that arise and study the incentive and welfare effects of the two IPR regimes of interest.

\section{IPRs and Crop-Improving R\&D in Agriculture}

The need to account explicitly for the nature of IPRs is given more urgency by the dramatic changes that have characterized the $R \& D$ enterprise in crop improvements and biotechnology over the last quarter of a century. Intellectual property protection in these areas has been strengthened enormously, leading to what amounts to a revolution in the set of opportunities facing innovators (Wright and Pardey, 2006). In the United States, following the 1980 landmark U.S. Supreme Court decision in Diamond v. Chakrabarty, a major change has been the extension of the applicability of standard utility patents to virtually any biologically based invention, if obtained through human intervention. That utility patents can be used for the products of plant breeding and biotechnology in agriculture was confirmed by the 2001 U.S. Supreme Court ruling in J.E.M. Ag Supply, Inc. v. Pioneer Hi-Bred International, Inc., which held that plant seeds and plants themselves (both traditionally bred or produced by genetic engineering) are patentable under U.S. law (Janis and Kesan, 2002).

Whereas the availability of utility patents for plant and animal innovations has also been introduced in many other developed countries, in most developing countries PBRs remain the strongest IPR protection instrument available. Indeed, in the international 
context the impetus to harmonize and strengthen IPRs in agriculture has resulted from the implementation of the TRIPS (trade related aspects of intellectual property rights) agreement of the World Trade Organization (WTO) (Moschini, 2004). A crucial feature of TRIPS is that it mandates that minimum standards of IPR protection be provided by each WTO member in each of the main areas of intellectual property that it covers. Specifically, patent protection must be accorded for both products and processes, for at least 20 years, in almost all fields of technology. But agriculture-related innovations enjoy a somewhat special treatment within TRIPS because plant and animal innovations need not be protected by patents, as long as a suitable sui generis protection is offered. Modern agriculture-related R\&D relies heavily on biotechnology innovations, as in the development of GM crop varieties, and it turns out that the flexibility provided by TRIPS extends further than plant and animal innovation: "essentially biological processes" may also be excluded from patentability (although patents must be provided for microorganisms, and for microbiological processes for producing plants or animals).

As noted, if plants and animals are excluded from patentability, then under TRIPS a sui generis IPR system must be provided. PBRs are commonly used internationally for plant varieties and appear to be the sui generis IPR system of choice for many countries, including virtually all developing countries. But, unlike utility patents, PBRs allow for a well-defined "research exception." That is, a protected variety may be used by others in their breeding programs aimed at developing a new variety. Thus, PBRs are clearly a weaker IPR protection instrument than patents, and whether the feature that separates these two IPR protection modes has important consequences for the innovation enterprise appears to be an important and yet unsettled question.

Concomitant with the rise of the importance of IPRs for agricultural $\mathrm{R} \& \mathrm{D}$, the last few decades have also witnessed a number of other critical developments. The secular trend in the decline of public R\&D relative to private R\&D (Fuglie et al., 1996) has intensified, and at present the private sector provides the bulk of biological research efforts in agriculture. Furthermore, the agricultural seed and chemical industries have undergone a tremendous consolidation. The earlier emphasis on the "life sciences" concept was abandoned because of a perceived lack of sufficient synergies between plant and human-health biotechnology. What has emerged, instead, is a strong consolidation between the seed and the agrochemical industrial segments aimed at exploiting the way modern GM varieties can complement 
and/or substitute for more traditional herbicide and pesticide products. A wave of acquisitions has resulted in a highly concentrated and integrated agro-chemical sector (UNCTAD, 2006).

In what follows, we develop a stylized model of innovation that features the biological resistance problem and the notion of adaptive destruction, and we do so in a more realistic institutional context that is consistent with the critical role played by IPRs and the market structure of the relevant industry. In particular, we compare and contrast the effects of two IPR regimes that differ precisely with respect to the presence of a research exemption, and, based on the foregoing discussion of consolidation in the agro-chemical sector, we cast the analysis in an imperfectly competitive setting (specifically, a duopoly).

\section{A Model of Sequential Innovation}

We imagine a situation in which a biological innovation, such as an improved seed variety resistant to a particular pest, can be developed upon a costly and risky R\&D process. Once developed, this innovation is adopted by a competitive sector, which we represent as made up of heterogeneous agents (e.g., farmers), that is, a population of potential costumers with differing willingness to pay for the innovation. Consistent with the notion of adaptive destruction discussed in the introduction, we also postulate that the value of the innovation is stochastically reduced to zero as time goes by. After the value of the existing innovation is thus destroyed, a new R\&D process can start to re-introduce the resistance trait of interest into the variety. Whether both firms can take part in this new innovation effort or only the firm that developed the improved variety in the initial innovations state depends on the nature of the IPR system. With an RE regime, both firms can participate in follow-on research. But if the IPR system does not allow for a research exemption (i.e., the FP regime), then we presume that only the winner of the initial stage can engage in efforts to restore the value of the variety after the onset of pest resistance. In either case, the winner of each race becomes the monopolist for the duration of the period in which innovation has a positive market value.

\subsection{Demand for innovation}

The derived demand $D(p)$ for the innovated product protected by IPRs is presumed downward sloping, as in Figure 1, where $v$ denotes the choke price. Given the exclusivity 
afforded by IPRs, the innovator can price monopolistically at $p^{M}$ so that, at the quantity demanded by users at that price, the marginal production cost $m c$ equals the marginal revenue $m r$. Expost, therefore, the innovator can extract a profit equal to $\pi$ (the green area in Figure 1), but some of the innovation's benefits also accrue to users, and relative to the ex post first-best use of the innovation there is also a deadweight loss- these two effects are labeled cs and $d w l$ in Figure 1 (e.g., Langinier and Moschini, 2002). To make the model tractable, we specifically postulate that there is a unit mass of end-users whose valuation of the new product is distributed uniformly on the interval $[0, v]$. For any given price of a new product, only users with valuations above that price will make a purchase. This implies that the monopolist faces a linear demand function of the form $D(p)=1-p / v$. If the marginal cost of production is constant, as in Figure 1, then without further loss of generality we can write $m c=0$. Under these assumptions, the monopolist's profit per unit of time is given by $\pi=v / 4$. Given this simplified demand structure, the surplus accruing to consumers under this (uniform) monopolistic pricing satisfies $c s=\pi / 2$.

\section{Figure 1. Demand for innovation}

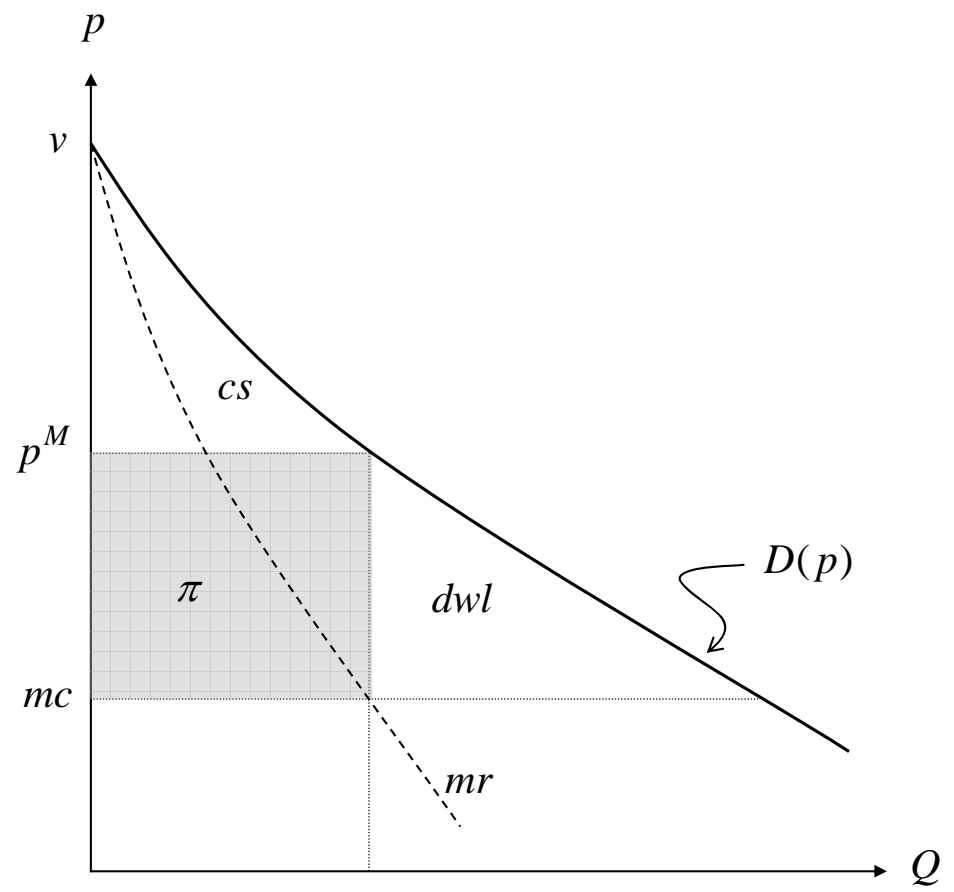




\subsection{Stochastic production of innovation}

At the start of the R\&D contest, or after the value of innovation is reduced to zero, the firms engage in an R\&D race in which the time of discovery is stochastic. As in other strategic R\&D models (e.g., Reinganum, 1989), we assume that innovations arrive according to a Poisson process with arrival rate $x$. Specifically, each firm that incurs a fixed R\&D cost $c$ at the start of a race has an instantaneous probability of producing a new product equal to $x$ (Denicolò, 1999), and the resulting stochastic time of the arrival of the innovation $\tau(x)$ is distributed independently with the (exponential) cumulative distribution function given by $\operatorname{Pr}[\tau(x) \leq z]=1-\exp (-x z)$.

The expected profit of a firm, when the total number of R\&D firms is equal to $n$, is derived in the standard fashion as follows. Denote by $\tau_{j}$ the random time of arrival of innovation for firm $j=1,2, \ldots, n$ and let $\hat{\tau}_{i}=\min _{j \neq i}\left\{\tau_{j}\right\}$. Then the probability that at least one

of firm $i$ s rivals has made a discovery at time $z$ is given by $\operatorname{Pr}\left[\hat{\tau}_{i} \leq z\right]=1-e^{-(n-1) x z}$. If we let $W$ denote the prize to the winner of the race and $r$ denote the common discount rate of all firms, the expected profit of firm $i$ when $n$ firms participate in the R\&D contest is obtained by integrating stochastic future returns with the joint density of $\left(\tau_{i}, \hat{\tau}_{i}\right)$ over the support in which $\tau_{i} \leq \hat{\tau}_{i}$, that is,

$$
V_{i}^{0}=\int_{0}^{\infty} \int_{s}^{\infty} e^{-r s} W x(n-1) e^{-(n-1) x z} x e^{-x s} d z d s-c
$$

where, again, $c$ is the fixed $\mathrm{R} \& \mathrm{D}$ cost. Thus, upon evaluating the integrals in (1), we obtain

$$
V_{i}^{0}=\frac{x W}{n x+r}-c .
$$

\subsection{Adaptive destruction}

A critical element of our model is the explicit modeling of the possible devaluation of the innovation due to pest adaptation. Such an "adaptive destruction" feature is captured by postulating that the value of the new product can be reduced to zero at each point in time with instantaneous probability $b$. That is, the stochastic arrival of adaptive destruction time $\tau_{A D}$ is distributed exponentially so that $\operatorname{Pr}\left[\tau_{A D} \leq z\right]=1-\exp (-b z)$. Admittedly, this convenient way to parameterize adaptive destruction is somewhat special, and there are 
other reasonable ways to model this process. First, we abstract from the possibility that adaptive destruction can be affected by some variables endogenous to the model (e.g., adoption). Such an extension is not crucial in our setting because we do not emphasize the diffusion phase of innovation but instead focus on the R\&D strategic interactions brought about by different IPR regimes. Second, a more realistic specification would perhaps assume that the instantaneous probability of destruction is increasing with time, so that the longer a variety is on the market, the higher is the likelihood of pest resistance making it obsolete. As explained in more detail in the next section, however, given the assumed structure of R\&D competition between firms, neglecting the possibility that the probability of resistance changes over time does not entail further loss of generality.

\section{Duopoly Model of Innovation}

As noted in the introduction, we capture the imperfectly competitive industry structure by postulating that there are at most two firms in any stage of the game. At the beginning of each stage, both firms decide whether to take part in the race. The winner of each race obtains IPRs that afford exclusivity in the final product market. Upon the onset of adaptive destruction, leading to the loss of market value for the innovated product, the race to produce a new product starts again. In this setting we interpret the RE regime as allowing both firms to enter the improvement race after the value of the innovated crop variety has been reduced to zero by adaptive destruction. Similarly, we interpret the stronger FP regime as restricting access to the improvement stage that follows adaptive destruction, so that only the winner of the first race has the right to practice the innovation for subsequent improvements. These interpretations are certainly consistent with the distinction between PBRs and patents discussed in the introduction, namely, that a patent gives full control of the improved variety to the innovator whereas PBRs allow others to use the variety for the development of further improvement. In what follows, we characterize the symmetric stationary equilibrium of the infinite horizon game under these two IPR regimes.

There are two assumptions in our model that make it tractable and may deserve further discussion. The first, and the most restrictive one, is the assumption on the timing of the $R \& D$ process: under the $R E$ regime, a firm can start a new $R \& D$ project only when the value of the previous innovation is reduced to zero. While assuming that a new R\&D project can be started at any point in time, after the previous inventive step was made, may appear 
more realistic, it would also complicate the analysis considerably. In order to focus on the sequential nature of innovation and its implications in the adaptive destruction context, we choose to abstract from the timing considerations by assuming that firms cannot preempt each other in the R\&D process.

The second simplifying assumption, mentioned in the previous section, is that of a constant hazard rate for the adaptive destruction process. This modeling choice is less restrictive than it might appear when one considers the implications of the previous assumption (on the timing of the $R \& D$ race). In particular, because the timing of $R \& D$ investment is exogenous, introducing the hazard function that is increasing in time is equivalent to simply decreasing the expected flow of profit from each innovation uniformly across the two IP regimes. While such a change will have an impact on the incentive to invest under the RE and FP regimes, there is an equivalent and more economical way to study this effect: one can increase the discount rate or the (constant) destruction hazard rate and compare the social ranking of the two IP regimes. This is, in fact, one of the comparative static exercises that we consider in our welfare analysis.

\subsection{Research exemption}

Under an RE regime, both firms can enter the race after the value of the crop has been reduced to zero. This implies that the game is essentially a sequence of identical races with two firms in each contest. The solution concept we employ in this paper is that of a Markov perfect equilibrium; i.e., we assume that strategies of the firms can depend only on the current state of the game (Fudenberg and Tirole, 1991). Let $\left(\sigma_{i}, \sigma_{j}\right) \in[0,1] \times[0,1]$ denote a stationary strategy profile of this game and let $V_{0}\left(\sigma_{i}, \sigma_{j}\right)$ denote the expected payoff of firm $i$ at the beginning of the race (i.e., when no firm has yet produced an innovation). Upon arrival of the innovation, the successful firm (which we label the "leader") can market the innovation. But because of the adaptive destruction feature discussed earlier, the value of this innovation is eventually destroyed. When that happens, a new innovation race can start, and under the RE regime both firms can participate. This means that the firm that is not successful in the firm innovation (which we label the "follower") still obtains value from the opportunity to take part in future innovation rounds. Thus, let $V_{L}\left(\sigma_{i}, \sigma_{j}\right)$ and $V_{F}\left(\sigma_{i}, \sigma_{j}\right)$ 
denote the expected payoffs of firm $i$ when it is the leader and when it is the follower, respectively. Then these functions are determined by the following conditions:

$$
\begin{aligned}
V_{0}\left(\sigma_{i}, \sigma_{j}\right)= & \sigma_{i} \sigma_{j}\left(\frac{x V_{L}\left(\sigma_{i}, \sigma_{j}\right)+x V_{F}\left(\sigma_{i}, \sigma_{j}\right)}{2 x+r}-c\right) \\
& +\left(1-\sigma_{i}\right) \sigma_{j} \frac{x V_{F}\left(\sigma_{i}, \sigma_{j}\right)}{x+r}+\left(1-\sigma_{j}\right) \sigma_{i}\left(\frac{x V_{L}\left(\sigma_{i}, \sigma_{j}\right)}{x+r}-c\right) \\
r V_{L}\left(\sigma_{i}, \sigma_{j}\right)= & \pi+b\left(V_{0}\left(\sigma_{i}, \sigma_{j}\right)-V_{L}\left(\sigma_{i}, \sigma_{j}\right)\right) \\
r V_{F}\left(\sigma_{i}, \sigma_{j}\right)= & b\left(V_{0}\left(\sigma_{i}, \sigma_{j}\right)-V_{F}\left(\sigma_{i}, \sigma_{j}\right)\right) .
\end{aligned}
$$

Equation (3) is the expected profit of firm $i$ for a given strategy profile $\left(\sigma_{i}, \sigma_{j}\right)$. Equation (4) is a standard Bellman equation, which says that the instantaneous return to being the innovation leader in this duopoly equals the flow of profit $\pi$ from marketing the innovation while it obtains plus the expected loss of value caused by the possibility of adaptive destruction. The Bellman equation (5) exhibits the property that there is value to being in this duopoly industry, even without any marketable product, because the possibility of adaptive destruction entails (in the RE regime) the possibility of taking part in future (and potentially profitable) R\&D contests.

Equations (3)-(5) allow us to derive the Markov perfect equilibrium (MPE) of the game under the RE regime. It turns out that the equilibrium behavior of firms depends on how the cost-to-profit ratio $c / \pi$ relates to the following threshold levels:

$$
\begin{aligned}
& t_{1}^{R E} \equiv \frac{x}{(r+b)(2 x+r)} \\
& t_{0} \equiv \frac{x}{(r+b)(x+r)} .
\end{aligned}
$$

Given that, the following proposition characterizes the MPE of the game under the RE regime.

Proposition 1. The symmetric MPE under the RE regime is given by the strategy profile $\left(\sigma_{R E}, \sigma_{R E}\right)$ that satisfies the following conditions:

$$
\text { If } \frac{\mathcal{C}}{\pi} \leq t_{1}^{R E} \text { then } \sigma_{R E}=1 .
$$




$$
\text { If } t_{1}^{R E}<\frac{c}{\pi}<t_{0} \text { then } \sigma_{R E} \in(0,1) \text {. }
$$

(iii) If $\frac{c}{\pi} \geq t_{0}$ then $\sigma_{R E}=0$.

A detailed proof of this result is provided in the Appendix, which also reports an explicit expression for the $\sigma_{R E}$ that applies to the case (ii). The structure of equilibrium under the RE regime is summarized graphically in the top part of Figure 2. Intuitively, both $t_{1}^{R E}$ and $t_{0}$ decrease in the discount and adaptive destruction rates, the higher values of which decrease expected profit and consequently incentives to invest in R\&D.

The fact that the two firms are ex ante identical justifies interest in the symmetric MPE. In such a context, a pure-strategy equilibrium in which both firms invest with probability one emerges when the R\&D cost $c$ is sufficiently low (relative to the per-period payoff $\pi$ ), that is, when $c / \pi \leq t_{1}^{R E}$. Similarly, when the R\&D cost is too high, that is, when $c / \pi \geq t_{0}$, both firms abstain from investing. For intermediate values of the $R \& D$ cost, that is, when $t_{1}^{R E}<c / \pi<t_{0}$, either firm would be willing to invest if the other firm did not, and would prefer to not invest if the other firm did. In addition to such asymmetric pure-strategy equilibria, there is a symmetric mixed-strategy MPE in which each firm invests with probability $\sigma_{R E} \in(0,1)$, as per Proposition 1 . The particular value of this probability, as well as the value of the threshold levels $t_{1}^{R E}$ and $t_{0}$, of course depends on the primitive parameters of the model (i.e., the Poisson arrival rates $x$ and $b$, and the discount rate $r$ ).

\subsection{Full patent}

Under the FP regime, the winner of the first race is the only one who has the right to practice the innovation for subsequent improvements. Let $V_{m}$ denote the value to the monopolist who has the property rights for the (existing) improved variety that is sold in the market, and let $V_{0}^{F P}$ denote the expected profit of the firm that has the exclusive right (because of the FP regime) to engage in the $\mathrm{R} \& \mathrm{D}$ process in order to produce the next generation of a product. Recalling equation (2), these value functions must satisfy

$$
V_{0}^{F P}=\frac{x V_{m}}{x+r}-c
$$


as well as the asset equation

$$
r V_{m}=\pi+b\left(V_{0}^{F P}-V_{m}\right) .
$$

Solving for the value functions, we obtain

$$
\begin{aligned}
& V_{m}=\frac{(\pi-b c)(x+r)}{(r+b)(x+r)-b x}, \\
& V_{0}^{F P}=\frac{(\pi-b c) x-c(r+b)(x+r)-b x}{(r+b)(x+r)-b x} .
\end{aligned}
$$

Recall that under the FP regime there is only one race at the start of the game, the winner of which will exclude the other firm from trying to improve the product in the future. In order to solve for the equilibrium we need to find the optimal strategies of the two firms in the initial race. It turns out that the equilibrium behavior of firms depends on how the cost-to-profit ratio $c / \pi$ relates to $t_{0}$ as defined in equation (7) and to the following threshold level:

$$
t_{1}^{F P} \equiv \frac{x(x+r)}{(2 x+r)(x+r+b) r+b x(x+r)} .
$$

Given that, the equilibrium under the FP regime is described in the following proposition.

Proposition 2. The symmetric MPE under the FP regime is given by the strategy profile $\left(\sigma_{F P}, \sigma_{F P}\right)$ that satisfies the following conditions:

$$
\text { If } \frac{c}{\pi} \leq t_{1}^{F P} \text { then } \sigma_{F P}=1
$$

(ii) If $t_{1}^{F P}<\frac{c}{\pi}<t_{0}$ then $\sigma_{F P} \in(0,1)$.

(iii) If $\frac{c}{\pi} \geq t_{0}$ then $\sigma_{F P}=0$.

A detailed proof of this result is provided in the Appendix, which also reports an explicit expression for the $\sigma_{F P}$ that applies to the case (ii). The structure of this equilibrium is illustrated in the bottom part of Figure 2.

As for the case of the RE regime, we find that the symmetric MPE can involve pure strategies with both firms investing when the R\&D cost is low enough (relative to the perperiod payoff $\pi$ ), or with both firms not investing when the R\&D cost is too high. For a 
specific domain of the cost-to-profit ratio, specifically $t_{1}^{F P}<c / \pi<t_{0}$, the two firms follow an equilibrium mixed strategy. It is informative to observe the relationship between threshold levels under the two regimes. First, note that the parameter $t_{0}$ is common to both regimes. Next, from the expressions given in (6) and (12) it can be verified that $t_{1}^{F P}>t_{1}^{R E}$. This result is intuitive because it implies that the level of the cost-to-profit ratio at which both firms start to invest with probability one is higher when the winner becomes a monopolist in the improvement game. A comparison of the two IPR regimes' equilibria is given in Figure 2.

\section{Figure 2. Equilibria under the two IPR alternatives}

\begin{tabular}{|c|c|c|c|}
\hline \multirow[t]{2}{*}{$\begin{array}{l}\text { Research } \\
\text { Exemption: }\end{array}$} & $\begin{array}{l}\text { Both } \\
\text { Invest }\end{array}$ & Mixed Strategy & No Investment \\
\hline & $t_{1}^{R E}$ & $t_{1}^{F P}$ & $t_{0}$ \\
\hline $\begin{array}{l}\text { Full } \\
\text { Patent: }\end{array}$ & Both Invest & $\begin{array}{l}\text { Mixed } \\
\text { Strategy }\end{array}$ & No Investment \\
\hline
\end{tabular}

\section{Comparing IPR Alternatives: Ex Ante Profits}

Having characterized the various equilibria that can emerge in our R\&D model, we can now compare the economic implications of the two IPR regimes of interest. Consider first the $e x$ ante expected payoff to the two firms. When firms follow a non-degenerate mixed strategy, they must be indifferent between the actions upon which they are randomizing. Given that not investing entails a zero expected payoff, it follows that the expected payoff of a mixed strategy that assigns nonzero probability to not investing is itself zero. Hence, we know that (a) in the interval $\left[t_{1}^{F P}, t_{0}\right]$, profits are zero under both IPR regimes; (b) in the interval $\left[t_{1}^{R E}, t_{1}^{F P}\right]$, profits are zero under the RE regime, and positive under the FP regime; and (c) in the interval $\left[0, t_{1}^{R E}\right]$, profits are positive under both IPR regimes. 
In the interval $\left[0, t_{1}^{F P}\right]$, both firms invest with probability one under the FP regime. Recalling equation (2), the ex ante expected profit of each firm in this case is given by

$$
\Pi_{0}^{F P}=\frac{V_{m} x}{2 x+r}-c
$$

where $V_{m}$ is the value of being the monopolist of the innovation (and of the right to pursue further innovations, upon the onset of pest resistance), as defined earlier. By using equation (10) we find that the ex ante expected profit can be written as $\Pi_{0}^{F P}=\pi \alpha_{F P}-c \beta_{F P}$, where

$$
\alpha_{F P} \equiv \frac{x(x+r)}{(2 x+r)(r+b+x) r}
$$

and $\beta_{F P} \equiv 1+b \alpha_{F P}$.

Similarly, in the interval $\left[0, t_{1}^{R E}\right]$, both firms invest with probability one under the RE regime. By using the expression of the proof of Proposition 1 in the Appendix, when $\sigma_{i}=\sigma_{j}=1$, the ex ante expected profit of each firm can be written as $\Pi_{0}^{R E}=\pi \alpha_{R E}-c \beta_{R E}$, where

$$
\begin{aligned}
& \alpha_{R E} \equiv \frac{x}{(2 x+r+b) r} \\
& \beta_{R E} \equiv \frac{(2 x+r)(r+b)}{(2 x+r+b) r} .
\end{aligned}
$$

From the foregoing equations it follows that $\alpha_{R E}>\alpha_{F P}$, and also that $\beta_{R E}>\beta_{F P}$. It follows that, for a given $\pi$, for low values of the cost parameter $c$, the ex ante expected profit is higher under the RE regimes, whereas for higher values of the cost parameter, the FP regime yields higher ex ante expected profit. More specifically, the ranking of ex ante expected profit under the two IPR regimes can be summarized as in the following proposition.

Proposition 3. The firm's expected profit under the RE regime is higher than the expected profit under the FP regime if and only if $\frac{c}{\pi} \leq \frac{\alpha_{R E}-\alpha_{F P}}{\beta_{R E}-\beta_{F P}} \equiv \tilde{t}$.

Figure 3 illustrates the expected profit functions under the two IPR regimes for a given level of the per-period profit (i.e., varying only the cost parameter while keeping the profit parameter fixed). In this graph, the threshold $\tilde{t}$, as defined in Proposition 3 , is the 
point at which $\Pi_{0}^{R E}=\Pi_{0}^{F P}$. As established in Proposition 3, Figure 3 shows that firms will ex ante prefer the RE regime - the weaker of the two IPR regimes-if $c$ is low enough, that is, as long as $c / \pi \leq \tilde{t}$.

\section{Figure 3. Comparison of ex ante profits}

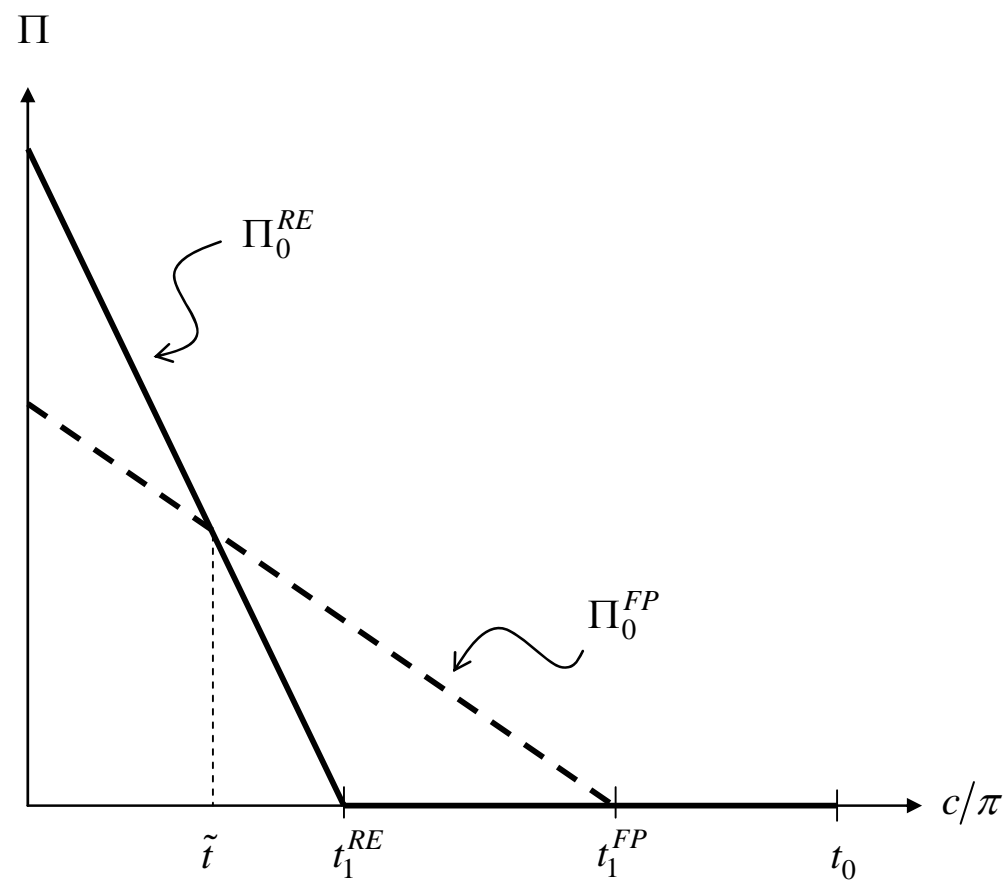

The intuition for this result can be obtained by considering the objective functions of each firm under the two IPR regimes when both firms invest with probability one in equilibrium, which happens in the interval $[0, \tilde{t}]$. From equation (3) we know that when both firms invest with probability one, the ex ante expected profit can be written as

$$
\Pi_{0}^{R E}=\frac{2 x\left(0.5 V_{L}(1,1)+0.5 V_{F}(1,1)\right)}{2 x+r}-c
$$

where $V_{L}(1,1)$ and $V_{F}(1,1)$ are defined in equations (4) and (5). Note that this can be interpreted as if each firm could pay amount $c$ to get a lottery with equal chances of becoming the leader and the follower, with corresponding expected payoff discounted by the factor $\frac{2 x}{2 x+r}$. On the other hand, from equation (13) we can write 


$$
\Pi_{0}^{F P}=\frac{2 x\left(0.5 V_{m}\right)}{2 x+r}-c .
$$

Similarly to the RE regime, this can be interpreted as each firm obtaining a lottery with equal probabilities of becoming a monopolist and dropping out of the race.

By comparing equations (17) and (18), it is now clear that the firm's ex ante profits are higher under the RE regime if and only if

$$
V_{L}(1,1)+V_{F}(1,1) \geq V_{m} .
$$

In other words, this would be the case when the expected payoff of the industry with two firms both investing with probability one is higher than the expected payoff of the industry with only one firm investing with probability one. Note that the industry with two firms will have both higher R\&D costs and a higher arrival rate of innovation, resulting in larger total profit when the R\&D cost is close to zero, as was previously shown.

This finding that firms may, ex ante, prefer the RE regimes is similar to the result of Bessen and Maskin (2006), who show that sometimes firms might prefer a weaker IP regime before the start of a race. This result in Bessen and Maskin arises because of the authors' assumption that innovations are complementary (diversity of innovation increases the probability of discovery, which is essential to keep the innovation process going). In our model, the downside of the FP regime from a firm's ex ante perspective is that losing the first innovation stage forecloses the possibility of profitable innovations in the future. This lost opportunity is particularly valuable when the $R \& D$ cost is relatively low.

\section{Comparing IPR Alternatives: Welfare}

In addition to the profit flowing to the firms, for the welfare comparison of the two IPR regimes we need to account for the surplus that flows to consumers whenever an innovation is commercialized (recall Figure 1).

\subsection{Expected consumer surplus}

Considering the RE regime first, let $S_{0}^{R E}$ denote the ex ante expected surplus to consumers

when the IPR system allows for a research exemption. Also, let $S_{1}^{R E}$ denote the expected consumer surplus, under this regime, whenever a successful innovation is achieved. Then $S_{0}^{R E}$ and $S_{1}^{R E}$ must satisfy the following asset equations: 


$$
\begin{aligned}
& S_{0}^{R E}=\left(\sigma_{R E}\right)^{2} \frac{2 x S_{1}^{R E}}{2 x+r}+2 \sigma_{R E}\left(1-\sigma_{R E}\right) \frac{x S_{1}^{R E}}{x+r} \\
& r S_{1}^{R E}=\frac{\pi}{2}+b\left(S_{0}^{R E}-S_{1}^{R E}\right) .
\end{aligned}
$$

As can be seen from equation (20), the expected $e x$ ante surplus depends on the number of firms investing in R\&D. With probability $\left(\sigma_{R E}\right)^{2}$ both firms invest in $\mathrm{R} \& \mathrm{D}$, and with probability $2 \sigma_{R E}\left(1-\sigma_{R E}\right)$ there is a single firm in the race. In the latter case the expected time until the arrival of innovation is longer, with instantaneous probability of discovery equal to $x$ (as opposed to $2 x$ when both firms invest). Equation (21) is a standard Bellman equation and represents the flow of consumer surplus from the existing innovation. According to this equation, the instantaneous expected return to consumers to having an innovation (i.e., $r S_{1}^{R E}$ ) is equal to the flow of consumer surplus while the innovation lasts (i.e., $\pi / 2$ ) plus the expected loss of this surplus due to the possibility of adaptive destruction (i.e., $\left.b\left(S_{0}^{R E}-S_{1}^{R E}\right)\right)$.

Solving equations (20) and (21) yields

$$
S_{0}^{R E}=\frac{\pi x\left[\sigma_{R E}(2 x+r)-\left(\sigma_{R E}\right)^{2} x\right]}{(r+b)(2 x+r)(x+r)-2 b x\left[\sigma_{R E}(2 x+r)-\left(\sigma_{R E}\right)^{2} x\right]} .
$$

To derive the consumer surplus under the FP alternative, consider the moment at which a firm has won the initial $\mathrm{R} \& \mathrm{D}$ contest such that this firm can now market the innovation at a profit flow of $\pi$ (as long as resistance does not arise). Upon the onset of resistance, the FP regime gives the firm the sole right to research for an improvement that overcomes the resistance. In such a setting, let $S_{1}^{F P}$ denote the expected consumer surplus when there is an innovation at hand, and let $S_{m}$ denote the expected consumer surplus when no innovation is available and only one firm (a monopoly) has the right to invest in R\&D. Then $S_{1}^{F P}$ and $S_{m}$ must satisfy the following asset equations:

$$
\begin{aligned}
& S_{m}=\frac{x S_{1}^{F P}}{x+r} \\
& r S_{1}^{F P}=\frac{\pi}{2}+b\left(S_{m}-S_{1}^{F P}\right) .
\end{aligned}
$$

Solving these two equations yields 


$$
S_{1}^{F P}=\left(\frac{\pi}{2}\right) \frac{x+r}{(x+r+b) r} .
$$

Now let $S_{0}^{F P}$ denote the ex ante expected consumer surplus under the FP regime. Given the equilibrium strategy profile, this expected consumer surplus would be equal to

$$
S_{0}^{F P}=\left(\sigma_{F P}\right)^{2} \frac{2 x S_{1}^{F P}}{2 x+r}+2 \sigma_{F P}\left(1-\sigma_{F P}\right) \frac{x S_{1}^{F P}}{x+r} .
$$

Using the solution in equation (25), it follows that

$$
S_{0}^{F P}=\frac{\pi x}{(x+r+b) r}\left(\frac{\sigma_{F P}(2 x+r)-\left(\sigma_{F P}\right)^{2} x}{(2 x+r)}\right) .
$$

The expected consumer surplus is increasing in $\pi$ (recall that the instantaneous consumer surplus in our model equals $\pi / 2$ ) and, as one would expect, it is decreasing in the adaptive destruction hazard rate.

\subsection{Welfare comparison: Analytic results}

By using the foregoing derivation for $S_{0}^{R E}$ and $S_{0}^{F P}$, we can unambiguously rank social welfare when the cost of $\mathrm{R} \& \mathrm{D}$, relative to the potential payoff of the innovation, in not too high.

Proposition 4. The RE regime results in a higher level of social welfare if $\frac{c}{\pi} \in[0, \tilde{t}]$.

To see why this result must hold, evaluate equations (22) and (27) at $\sigma_{F P}=\sigma_{R E}=1$. It can then be verified that when both firms invest with probability one, the consumer surplus functions satisfy $S_{0}^{R E}(1)>S_{0}^{F P}(1)$, and so we conclude that in the domain of interest, the RE regime results in a higher level of social welfare. This result is very intuitive. Because both firms invest with probability one under either regime in the domain $c / \pi \in\left[0, t_{1}^{R E}\right]$, the RE regime results in a higher rate of innovation for all improvement stages (after the onset of resistance), and so in this domain consumers are necessarily better off under the RE regime. Furthermore, as long as $c / \pi \in[0, \tilde{t}]$, we have shown that firms also ex ante prefer the RE regime. Because $\tilde{t}<t_{1}^{R E}$, we can then conclude that in the domain of interest social welfare is higher with the RE regime. 


\subsection{Welfare comparison: Numerical results}

Proposition 4 does not rank the two IPR regimes when R\&D cost is sufficiently high, that is, when $c / \pi \in\left[\tilde{t}, t_{0}\right]$. To compare social welfare in this domain, we need to take into account the types of equilibria that can occur. In particular, we have to distinguish three cases:

(A) $(c / \pi) \in\left[t_{1}^{F P}, t_{0}\right]$. In this interval, firms' profits are equal to zero under both regimes, so the social welfare under both regimes is equal to the corresponding consumer surplus.

(B) $(c / \pi) \in\left[t_{1}^{R E}, t_{1}^{F P}\right]$. In this interval, firms make positive profit under the FP regime, and social welfare under the FP regime is equal to the sum of profits and consumer surplus.

(C) $(c / \pi) \in\left[\tilde{t}, t_{1}^{F P}\right]$. In this interval, firms make positive profit under both regimes, and both welfare functions are equal to the sum of profit and consumer surplus.

Because the equilibrium strategies $\sigma_{F P}$ and $\sigma_{R E}$ are in general functions of $\pi$ and $c$ parameters (see the Appendix), it does not appear possible to provide an analytic result that would establish unambiguously the welfare ranking of the two IPR regimes. To gain some insights, here we resort to comparing welfare numerically. In particular, we normalize profit to be equal to one $(\pi=1)$ and study social welfare as a function of $c$ for a given set of parameter values. We calibrate the model so that the resulting durations of an innovation race and the useful life of a new variety are broadly consistent with what is observed in the plant breeding industry. In particular, we perform our numerical analysis for the following parameter values. The discount factor is fixed at $r=0.05$. The arrival rate of innovation $x$ is equal to either 0.25 or 0.125 , which corresponds to the expected times until discovery of 4 or 8 years, respectively. The destruction rate $b$ is equal to $0.2,0.1$, or 0.05 , which corresponds to the expected lifetime of a new variety of 5, 10, or 20 years, respectively. The resulting threshold values (which determine the domains of equilibria $\mathrm{A}, \mathrm{B}$, and $\mathrm{C}$ for which numerical analysis is performed) are given in Table 1. 
Table 1. Threshold values

\begin{tabular}{|c|c|c|c|c|}
\hline$x=0.125, b=0.1$ & $\tilde{t}=1.32$ & $t_{1}^{R E}=2.78$ & $t_{1}^{F P}=3.47$ & $t_{0}=4.76$ \\
\hline$x=0.25, b=0.1$ & $\tilde{t}=1.02$ & $t_{1}^{R E}=3.03$ & $t_{1}^{F P}=4.05$ & $t_{0}=5.56$ \\
\hline$x=0.125, b=0.05$ & $\tilde{t}=1.69$ & $t_{1}^{R E}=4.17$ & $t_{1}^{F P}=4.89$ & $t_{0}=7.14$ \\
\hline$x=0.25, b=0.05$ & $\tilde{t}=1.22$ & $t_{1}^{R E}=4.55$ & $t_{1}^{F P}=5.61$ & $t_{0}=8.33$ \\
\hline$x=0.125, b=0.2$ & $\tilde{t}=0.91$ & $t_{1}^{R E}=1.67$ & $t_{1}^{F P}=2.19$ & $t_{0}=2.86$ \\
\hline$x=0.25, b=0.2$ & $\tilde{t}=0.77$ & $t_{1}^{R E}=1.82$ & $t_{1}^{F P}=2.61$ & $t_{0}=3.33$ \\
\hline
\end{tabular}

For each pair $(x, b)$ we computed the social welfare functions under RE and under the FP regimes on the interval $c \in\left[\tilde{t}, t_{0}\right]$ (we already know the welfare ranking for the range $c \in[0, \tilde{t}]$ from Proposition 4). These computed welfare levels are graphed in Figure 4, where welfare is measured on the vertical axes and $R \& D$ cost on the horizontal axes (welfare under the RE regimes is represented by the dashed line and welfare under the FP regime is represented by the solid line).

Consistent with what was established in Proposition 4, at $c=\tilde{t}$ social welfare is higher under the RE regime. But as $c$ increases, the numerical analysis shows that at some point the FP regime dominates. Hence, this suggests the general conclusion that for the parameter values, which reflect the nature of the plant breeding industry, the FP regime is socially optimal when the cost of innovation is relatively high. In this case the stronger incentives provided by the FP regime lead to a higher flow of innovations and higher social welfare. On the other hand, when the cost of $\mathrm{R} \& \mathrm{D}$ is relatively low, a weaker intellectual property regime such as RE is beneficial from the social point of view. Additional numerical analysis, not reported here for space reasons, shows that this general conclusion appears robust to changes in the underlying parameter values well outside the range explored in Figure 4. 
Figure 4. Welfare under FP (solid line) and RE (dashed line) regimes
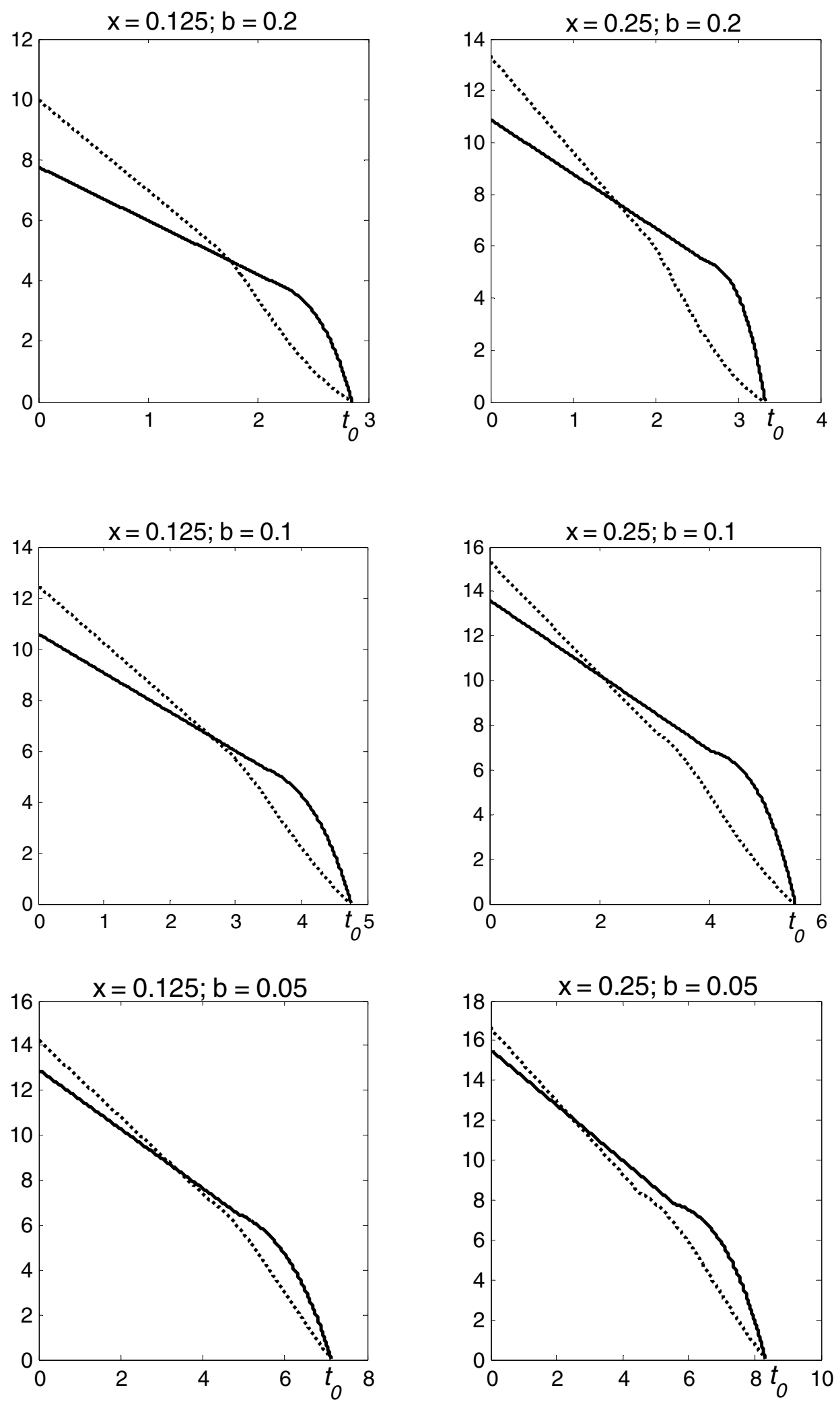


\subsection{Licensing}

The model of this article has assumed that the patent-holder does not license its innovation to the competitor. It should be clear at the outset that the only meaningful licensing in our context is for the right to innovate. Because the model limits the scale of R\&D activity, theoretically there might be a scope for licensing under the FP regime (under the RE regime the follower always has access to innovation by definition). In particular, as shown earlier, there exists a region of the parameter space in which the joint profit of the two firms is larger than the monopolist's profit, which would make licensing profitable. Because there is no asymmetric information in the model, the monopolist would be able to extract the entire expected surplus through licensing. In such a case both expected consumer surplus and profit will increase. Hence, licensing would make the total welfare under the FP regime higher than without licensing while having no welfare impact under the RE regime. Therefore, we conclude that assuming away the possibility of licensing biases our results to some degree in favor of the RE regime.

\section{Conclusion}

The analysis of this paper contributes to the discussion of economic policies that may mitigate problems caused by pest resistance. In contrast to much of the previous literature, which deals with this issue within the renewable or non-renewable resource framework, this study has focused on the role of an institutional factor that is having an increasing influence on the R\&D process in plant breeding, namely, the nature of intellectual property rights. In particular, we construct an explicit model of the two types of intellectual property regimes that are widely used to protect plant innovations and study the effect of the resulting market structure on the incentive to invest in plant breeding R\&D and social welfare. The two types of intellectual property protection in question are those provided by utility patents and those provided by Plant Variety Protection certificates. The latter intellectual property regime results in a weaker form of protection because it allows for a well-defined research exemption provision. We specifically focus on the adaptive destruction process, which arises because of the reduction of the market value of the crops due to pest adaptation.

The model that we have analyzed is necessarily very stylized, yet it yields some interesting analytic and numerical results. Specifically, we find that the welfare ranking of the intellectual property regimes depends on the cost-to-profit ratio. In our model, the R\&D 
activity requires a fixed outlay at the start of the innovation race, which can be interpreted as the cost of starting and maintaining a new plant breeding program. The analytic results established in this paper imply that when the cost is relatively low, the research exemption regime yields a higher welfare. Our numerical results suggest that for a high cost-to-profit ratio it is the full patent regime that provides better incentives to invest in $R \& D$ and yields higher social welfare. These results are established by calibrating the model so that the expected durations of innovation and adaptive destruction processes are broadly representative of the plant breeding industry. An additional result established in this paper implies that when the value of the cost-to-profit ratio is low, firms ex ante prefer the research exemption regime, even though it is a weaker form of protection (this conclusion is similar to that obtained by Bessen and Maskin [2002] in a different model of sequential innovation).

In addition to deriving the profit and welfare effects of alternative intellectual property regimes used in the plant breeding, the analysis of this paper also emphasizes that the form of intellectual property rights defines the market structure of the industry, and that this market structure will not necessarily coincide with the two extreme cases of monopoly and perfect competition that have been the focus of the majority of previous studies. Future work toward the derivation of cogent implications for policymakers concerned with the adaptive destruction problem, therefore, may need to account more explicitly for the (sometimes subtle) effects of alternative institutions that establish and strengthen intellectual property rights. 


\section{References}

Alix-Garcia, J., and Zilberman, D. (2005) “The effect of market structure on pest resistance buildup”, Working Paper, available at SSRN: http://ssrn.com/abstract=836164

Bessen, J., and Maskin, E. (2006) "Sequential innovation, patents, and imitation", Working Paper, Research on Innovation, Boston, MA.

Brock, W.A. and Xepapadeas, A. (2003) "Valuing Biodiversity from an Economic Perspective: A Unified Economic, Ecological, and Genetic Approach”, American Economic Review, 93(5):1597-1614.

Denicolò, V. (1999) “The optimal life of a patent when the timing of innovation is stochastic", International Journal of Industrial Organization 17:488-501.

Denicolò, V. (2000) “Two-stage patent races and patent policy", RAND Journal of Economics 31(3):488-501.

Fisher, C., and Laxminarayan, R. (2004) "Keeping one row ahead of the bugs: The economics of pest resistance to transgenic crops", Resources 152: 5-8.

Fisher, C., and Laxminarayan, R. (2005) "Sequential development and exploitation of an exhaustible resource: Do monopoly rights promote conservation?" Journal of Environmental Economics and Management 49:500-515.

Fudenberg, D., and Tirole, J. (1991) Game Theory, Cambridge, MA: The MIT Press.

Fuglie, K., Ballenger, N., Day, K., Klotz, C., Ollinger, M., Reilly, J., Vassavada, U., and Yee, J. (1996) Agricultural Research and Development: Public and Private Investments under Alternative Markets and Institutions. USDA/ERS, Agricultural Economics Report No. 735. Washington, D.C.

Goeschl, T., and T. Swanson. (2002a) On the Economic Limits to Technological Potential: Will Industry Resolve the Resistance Problem? In: T. Swanson (ed.) The Economics of Managing Biotechnologies, Kluwer: Netherlands.

Goeschl, T., and Swanson, T.M. (2002b) "Lost horizons: The non-cooperative management of an evolutionary biological system", Fondazione Eni Enrico Mattei, Nota di Lavoro 89.

Goeschl, T., and Swanson, T.M. (2003a) "On biology and technology: The economics of managing biotechnologies”, FEEM Working Paper 42.03, Fondazione ENI Enrico Mattei. 
Goeschl, T., and Swanson, T.M. (2003b) "Pests, plagues, and patents", Journal of the European Economic Association 1(2-3):561-575.

Green, J., and Scotchmer, S. (1995) "On the division of profit in sequential innovation". RAND Journal of Economics 6(1), 20-33.

Hueth, D., and Regev, D. (1974) "Optimal agricultural pest management with increasing pest resistance". American Journal of Agricultural Economics 56:543-52.

Hurley, T.M., S. Secchi, B. Babcock, and R. Hellmich (2002) "Managing the risk of European corn borer resistance to Bt corn”, Environmental and Resource Economics 22:537-558.

Janis, M.D., and Kesan, J.P. (2002) "Intellectual property protection for plant innovation: Unresolved issues after J.E.M. v. Pioneer", Nature Biotechnology, 20:1161-1164.

Just, R.E., Alston, J.M., and Zilberman, D. (eds.) (2006) Regulating Agricultural Biotechnology: Economics and Policy Springer: New York.

Langinier, C., and Moschini, G. (2002) “The economics of patents.” In: M. Rothschild and S. Newman (eds.) Intellectual Property Rights in Animal Breeding and Genetics, Wallingford, Oxon, UK: CABI.

Moschini, G. (2004) "Intellectual property rights and the World Trade Organization: Retrospect and prospects.” In: G. Anania, M. Bohman, C. Carter, \& A. McCalla (eds), Agricultural Policy Reform and the WTO, Aldershot, UK: Edward Elgar Publishing.

Moschini, G., and Yerokhin, O. (2006) "Patents, Research Exemption, and the Incentive for Sequential Innovation.” Working Paper \# 06019, Department of Economics, Iowa State University, Ames, Iowa.

Noonan, D. (2002) "An economic model of a genetic resistance commons: Effects of market structure applied to biotechnology in agriculture.” In: R. Laxminarayan, (ed.) Battling Resistance to Antibiotics and Pesticides: An Economic Approach, Washington DC: RFF Press.

O’Donoghue, T. (1998) “A patentability requirement for sequential innovation", RAND Journal of Economics 29(4):654-679.

Palumbi, R. (2001) "Humans are world's greatest evolutionary force", Science, 293(5536):1786-1790. 
Reinganum, J. (1989) “The timing of innovation: Research, development, and diffusion.” In: R. Schmalensee and R.D. Willig, (eds.) Handbook of Industrial Organization, Vol. 1, Amsterdam: North-Holland.

Swanson, T. (ed.) (2002) The Economics of Managing Biotechnologies, Netherlands: Kluwer.

UNCTAD (United Nations Conference on Trade and Development) (2006) Tracking the Trend Towards Market Concentration: The Case of the Agricultural Input Industry, UNCTAD/DITC/COM/2005/16.

Wright, B.D., and Pardey, P.G. (2006) "The evolving rights to intellectual property protection in the agricultural biosciences", International Journal of Technology and Globalization 2:12-29. 


\section{Appendix}

\section{Proof of Proposition 1 (RE regime)}

Substituting (4) and (5) into (3) we obtain

$$
\begin{aligned}
V_{0}\left(\sigma_{i}, \sigma_{j}\right)= & \sigma_{i} \sigma_{j}\left(\frac{x}{(2 x+r)} \frac{\pi}{(r+b)}+\frac{2 x}{(2 x+r)} \frac{b V_{0}\left(\sigma_{i}, \sigma_{j}\right)}{(r+b)}\right)+\left(1-\sigma_{i}\right) \sigma_{j}\left(\frac{x}{x+r}\right) \frac{b V_{0}\left(\sigma_{i}, \sigma_{j}\right)}{r+b} \\
& +\left(1-\sigma_{j}\right) \sigma_{i}\left(\frac{x}{x+r} \frac{\pi+b V_{0}\left(\sigma_{i}, \sigma_{j}\right)}{r+b}\right)-c\left(\sigma_{i} \sigma_{j}+\left(1-\sigma_{j}\right) \sigma_{i}\right)
\end{aligned}
$$

Rearranging:

$$
V_{0}\left(\sigma_{i}, \sigma_{j}\right)=\frac{1}{\Phi\left(\sigma_{i}, \sigma_{j}\right)}\left[\sigma_{i} \sigma_{j} \frac{x}{(2 x+r)} \frac{\pi}{(r+b)}+\left(1-\sigma_{j}\right) \sigma_{i} \frac{x}{(x+r)} \frac{\pi}{(r+b)}-c \sigma_{i}\right],
$$

where

$$
\Phi\left(\sigma_{i}, \sigma_{j}\right) \equiv 1-\frac{2 x b \sigma_{i} \sigma_{j}}{(2 x+r)(r+b)}-\frac{x b\left(\left(1-\sigma_{i}\right) \sigma_{j}+\left(1-\sigma_{j}\right) \sigma_{i}\right)}{(x+r)(r+b)} .
$$

Part (i). First note that if $\sigma_{j}=1$, then

$$
V_{0}\left(\sigma_{i}, \sigma_{j}\right)=\frac{\sigma_{i}}{\Phi\left(\sigma_{i}, 1\right)}\left[\frac{x}{(2 x+r)} \frac{\pi}{(r+b)}-c\right] .
$$

Note also that the first term $\frac{\sigma_{i}}{\Phi\left(\sigma_{i}, 1\right)}=\sigma_{i}\left(1-\frac{x b}{(x+r)(r+b)}\left(1+\frac{r \sigma_{i}}{2 x+r}\right)\right)^{-1}$, is increasing in $\sigma_{i}$. This implies that if $\frac{x}{(2 x+r)} \frac{1}{(r+b)}>\frac{c}{\pi}$ then $\sigma_{i}=1$ is the best response and both firms invest with probability 1 in equilibrium.

Part (ii). For notational simplicity let $\sigma_{R E} \equiv \sigma^{*}$. In the interior equilibrium, firm $i$ is indifferent between investing and not for any given $\sigma_{j}$. Then the equilibrium symmetric strategy $\sigma_{i}=\sigma_{j}=\sigma^{*}$ must satisfy $V_{0}\left(1, \sigma^{*}\right)=V_{0}\left(0, \sigma^{*}\right)$, that is,

$$
\frac{1}{\Phi\left(1, \sigma^{*}\right)}\left[\sigma^{*} \frac{x}{(2 x+r)} \frac{\pi}{(r+b)}+\left(1-\sigma^{*}\right) \frac{x}{(x+r)} \frac{\pi}{(r+b)}-c\right]=0
$$

from which we can solve

$$
\sigma^{*}=\frac{(2 x+r)}{x}\left(1-\frac{c}{\pi} \frac{(r+b)(x+r)}{x}\right) .
$$


Next, the condition $0<\sigma^{*}<1$ implies that this solution applies if and only if

$$
\frac{x}{(r+b)(2 x+r)}<\frac{c}{\pi}<\frac{x}{(r+b)(x+r)} .
$$

Part (iii). Note that if $\sigma_{j}=0$ then

$$
V_{0}\left(\sigma_{i}, \sigma_{j}\right)=\frac{\sigma_{i}}{\Phi\left(\sigma_{i}, 0\right)}\left[\frac{x}{(x+r)} \frac{\pi}{(r+b)}-c\right] .
$$

Clearly, if $\frac{x}{(x+r)} \frac{1}{(r+b)}<\frac{c}{\pi}$, then $\sigma_{i}=0$ is a best response and none of the firms invests in equilibrium.

\section{Proof of Proposition 2 (FP regime)}

Consider the initial stage of the game. For a given strategy profile $\left(\sigma_{i}, \sigma_{j}\right) \in[0,1]^{2}$ the payoff of firm $i$ in the initial stage is given by

$$
V_{0}\left(\sigma_{i}, \sigma_{j}\right)=\sigma_{i} \sigma_{j}\left(\frac{V_{m} x}{2 x+r}-c\right)+\sigma_{i}\left(1-\sigma_{j}\right)\left(\frac{V_{m} x}{x+r}-c\right),
$$

where $V_{m}$ is given by equation (10). Rearranging,

$$
V_{0}\left(\sigma_{i}, \sigma_{j}\right)=\sigma_{i}\left(\frac{V_{m} x}{x+r}\left(1-\frac{\sigma_{j} x}{2 x+r}\right)-c\right) .
$$

Part (i). Note that if $\sigma_{j}=1$ we have

$$
V_{0}\left(\sigma_{i}, \sigma_{j}\right)=\sigma_{i}\left(\frac{V_{m} x}{2 x+r}-c\right)
$$

This implies that if $\frac{V_{m} x}{2 x+r} \geq c$ then $\sigma_{i}=1$ is the best response and both firms invest with probability 1 in equilibrium. Substituting for $V_{m}$ yields

$$
\frac{c}{\pi} \leq \frac{x(x+r)}{(2 x+r)(x+r+b) r+b x(x+r)} .
$$

Part (ii). For notational simplicity let $\sigma_{F P} \equiv \sigma^{*}$. In the interior equilibrium, firm $i$ is indifferent between investing and not for any given $\sigma_{j}$. Then the equilibrium symmetric strategy profile $\sigma_{i}=\sigma_{j}=\sigma^{*}$ must satisfy $V_{0}\left(1, \sigma^{*}\right)=V_{0}\left(0, \sigma^{*}\right)$, from which we obtain

$$
\sigma^{*}=\frac{V_{m} x-c(x+r)}{V_{m} x}\left(\frac{2 x+r}{x}\right)
$$


Again, the condition $0<\sigma^{*}<1$ implies that this solution applies if and only if

$$
\frac{x(x+r)}{(2 x+r)(x+r+b) r+b x(x+r)}<\frac{c}{\pi}<\frac{x}{(r+b)(x+r)} \text {. }
$$

Part (iii). Note that if $\sigma_{j}=0$, then

$$
V_{0}\left(\sigma_{i}, \sigma_{j}\right)=\sigma_{i}\left(\frac{V_{m} x}{x+r}-c\right) .
$$

This implies that if $\frac{V_{m} x}{x+r} \leq c$ then $\sigma_{i}=0$ is the best response and none of the firms invests in equilibrium. This condition can be further simplified, by using the expression for $V_{m}$, to obtain

$$
\frac{c}{\pi} \geq \frac{x}{(x+r)(r+b)}
$$

